\title{
Central Venous Access through the External Jugular Vein in Children Submitted to Bone Marrow Transplantation
}

\author{
José Luiz de Godoy ${ }^{1 *}$, Edson Keity Otta ${ }^{1}$, Ricardo Atsumori Miyazaki ${ }^{1}$, Marco Antonio \\ Bitencourt $^{2}$ and Ricardo Pasquini ${ }^{2}$ \\ ${ }^{1}$ Disciplina de Cirurgia Pediátrica; ${ }^{2}$ Serviço de Transplante de Medula Óssea; Hospital de Clínicas; Universidade \\ Federal do Paraná; Curitiba - PR - Brazil
}

\begin{abstract}
Establishment of long-term central venous access is a sine qua non step for bone marrow transplantation in children. Most frequently, long-term central venous access has been obtained via blind percutaneous cannulation of subclavian and internal jugular veins or via internal jugular vein cutdown. In order to avoid some potential minor and major complications associated with the subclavian or internal jugular approaches, the authors describe an easy, simple and safe method for central venous access through an external jugular vein cutdown that should be of interest to readers involved in the field of bone marrow transplantation. It should be also considered for children as well as adults needing central venous access via an external catheter - or totally implantable port - for reasons other than bone marrow transplantation, such as total parenteral nutrition and administration of chemotherapeutic agents.
\end{abstract}

Key words: Central venous access, external jugular vein, bone marrow transplantation, catheter

\section{INTRODUCTION}

Insertion of a long-term central venous catheter is a sine qua non step for bone marrow transplantation in children. Access to the central venous system obviates the need for repeated and progressively more difficult venous catheterization and venipuncture in these children. Most frequently, central venous access is achieved via percutaneous cannulation of the subclavian and internal jugular veins or via internal jugular vein cutdown technique. However, these routes can have some potential minor and major complications associated with the blind percutaneous technique. These include pneumothorax, hemothorax, air embolization, chylothorax, carotid or subclavian artery puncture and hemostasis control in children who have bleeding diatheses (Gauderer, 1992; Stovroff and Teague, 1998). Improvement of subclavian and internal jugular vein percutaneous cannulation using ultrasound-guided technique appears to distinguish arterial from venous flow, but it can be unsuccessful and has not been shown to reduce the incidence of complications (Lobe et al., 1993; Nosher et al., 1994; Slama et al., 1997). Albeit rare, lethal complications have also been described even if central catheter placement is performed as an elective procedure in expertised hands (Bagwell et al., 2000).

From a surgical point of view, an easier and simpler alternative with minimal risk during insertion could be the route through the external jugular vein cutdown. However, little is know

\footnotetext{
* Author for correspondence
} 
about this technique. The aim of this study was to assess if long-term central venous access through an external jugular vein cutdown was safe and reliable in children submitted to bone marrow transplantation.

\section{PATIENTS AND METHODS}

This is a prospective study involving insertion of central venous catheter (double-lumen Hickman catheter) (Hickman et al., 1979) in 100 children submitted to bone marrow transplantation, from July 1999 to July 2002, refered to our bone marrow transplantation service. All surgical procedures were performed by the same surgical team.

Under general anesthesia, with the child in the Trendelenburg position, the child's head is turned at a $45^{\circ}$ angle to the contralateral side. This maneuver allows easy visualization of the external jugular vein. A short transverse cervical incision $(1-2 \mathrm{~cm})$ is made directly over the external jugular vein approximately $2-3 \mathrm{~cm}$ above the clavicle. The external jugular vein is just beneath the platysma muscle and can be gently isolated over a hemostatic. If the external jugular vein is not suitable for use, the incision can be extended medially and the internal jugular vein can be dissected (Fig. 1). Then the external jugular vein is double repaired with $3 / 0$ cotton. The catheter is tunneled from the entrance site on the anterior chest wall, over the clavicle, to the cervical incision. A short transverse venotomy is made. A $6 / 0$ vascular suture is placed at the angles of the venotomy. Before the venous insertion, the catheter must be trimmed to length so that the tip will lie in the right atrium-vena cava junction. As the catheter is advanced into the external jugular vein, $20 \mathrm{~mL}$ of isotonic saline solution is injected to help to direct the tip into the superior vena cava. The tip sometimes can travel into a major vein (ipsilateral or contra-lateral subclavian or internal jugular vein). This problem is easily recognized under fluoroscopy or on a chest radiograph. When it occurs, the catheter is withdrawn slightly, twisted, and reintroduced. Under fluoroscopic guidance - or on a mandatory post-procedure chest radiograph - the tip of the catheter is confirmed to be in the right atrial-vena caval junction. No radiographic contrast was used in any child. The venotomy is closed with $6 / 0$ interrupted vascular suture or the distal tie is ligated and the catheter is secured in the vein by ligating the proximal tie. The catheter function is checked. Any sharp bend at the insertion site into the vein is avoided. The system is flushed with heparinized saline (10 $\mathrm{U} / \mathrm{mL}$ ). Hemosthasis is reviewed. The cervical incision is closed in two layers (platysma muscle with soft tissue and the skin). The catheter is fixed to the skin in the entrance site on the chest wall. Perioperative antibiotic prophylaxis appears unnecessary.

\section{RESULTS}

Central venous catheters were inserted through the internal jugular vein cutdown in 20 children because the ipsilateral external jugular vein was not found or, most frequently, it was too small, avoiding progression of the catheter. These 20 children were excluded from the study. In 80 children, 82 central venous catheters were inserted through the external jugular vein cutdown. Catheters were inserted through the external jugular vein, 70 were right sided and 12 were left sided. There were 50 boys and 30 girls.

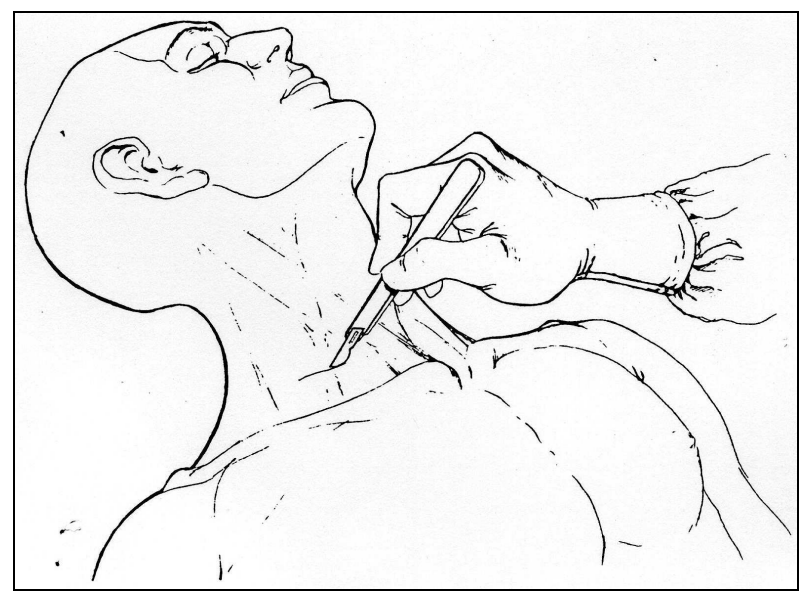

Figure 1 - Cervical incision. A short transverse cervical incision $(1-2 \mathrm{~cm})$ is made directly over the external jugular vein approximately $2-3 \mathrm{~cm}$ above the clavicle.

The underlying diseases were severe aplastic anemia $(\mathrm{n}=29)$, Fanconi anemia $(\mathrm{n}=17)$, acute lymphoblastic leukemia $(\mathrm{n}=14)$, acute myelogenous leukemia $(\mathrm{n}=10)$, chronic myelogenous leukemia $(n=4)$, severe combined immunodeficiency syndrome $(\mathrm{n}=2)$, WiskottAldrich syndrome $(n=2)$, dyskeratosis congenita 
$(\mathrm{n}=1)$ and adrenoleukodistrophy $(\mathrm{n}=1)$. In 67 children the procedure was done as a primary central venous access, whereas the other 13 children had a previous access through the internal jugular vein cutdown. They were performed by another surgical team or the children came from another hospital. The average age of the children at the operation was 113.5 months (range 11 months to 16 years). The median duration of catheter placement was 106.9 days (range 43 to 323 days). Hemorrhage and local infection in the cervical incision or in the entrance site on the chest wall were not observed in any child. Thrombotic and occlusive complications were not observed in any child. One child was reoperated one month later because of inadvertent catheter dislodgement which forced the skin of the cervical region. The catheter was not removed but reintroduced and the external jugular vein was ligated around the catheter. Four children had the catheter removed because of bacterial colonization of the catheter and another catheter was inserted in the contralateral external jugular vein in two children. No other complication related to this approach was observed in any child.

\section{DISCUSSION}

This study describes an easy, simple and safe method of long-term central venous access through the external jugular vein cutdown in children that should be of interest to readers involved in the field of bone marrow transplantation. The external jugular vein approach allowed us a successful insertion rate of $80 \%$ in long-term central venous access for children submitted to bone marrow transplantation.

The surgical team involved in bone marrow transplantation should consider that children refered to bone marrow transplantation may need repeated central venous access because of perforation or colonization of the catheter and occlusive complications (Gauderer, 1992 ; Nosher et al., 1994). Further, a second bone marrow transplantation might be necessary, particularly in bone marrow rejection or disease relapse. Considering the simplicity and safety of the central venous access described in this article, it is a very attractive first choice for central venous access in children submitted to bone marrow transplantation.
We found only one minor complication related to this method, which happened at the beginning of this study. It was caused by the catheter being left too superficial in the cervical incision, probably because the cervical incision was closed in only one layer. The child had to be reoperated to avoid erosion of the cervical incision by the catheter. Since then, we have always closed the cervical incision in two layers to prevent this complication. When using central venous access through the external jugular vein, two pitfalls can be prevented by appropriate placement of the catheter. First, Hickman-type silicone catheters placed in the superior vena cava with subsequent tunneling of the catheter along the chest wall often produce a sharp bend at the insertion site into the vein. This in turn may cause collapse of the catheter lumen, specially when negative (draw) pressure is applied (Fischmeister et al., 2000). Second, sometimes it is not easy for the surgeon to access accurately how much catheter will be needed to place the tip at the right atrium-vena cava junction, specially in obese children. In this instance it is prudent to leave the Dacron cuff higher in the tunnel prior to placing the catheter in the vein so that if the catheter is slightly longer it can be pulled back allowing the cuff to remain positioned in the tunnel. The consequence of this manoeuver is that, if the catheter is perfectly positioned on the initial try, the cuff will be higher than normal. This is important only at the time of catheter removal, when a smalll second counter-incision may be necessary to dissect the Dacron cuff from the tunnel.

The central venous access trough the external jugular vein cutdown described in this work is our method of choice to obtain central venous access in children who will undergo bone marrow transplantation. It should be also considered for children as well as adults needing central venous access via an external catheter - or totally implantable port - for reasons other than bone marrow transplantation, such as total parenteral nutrition and administration of chemotherapeutic agents.

\section{RESUMO}

O estabelecimento de um acesso venoso central de longa duração é uma condição sine qua non para realizar o transplante de medula óssea em crianças. 
Com frequência, este acesso tem sido obtido através da punção percutânea das veias subclávia e jugular interna ou via dissecção da jugular interna. Com o objetivo de evitar algumas complicações maiores e menores associadas com a subclávia e a jugular interna, os autores descrevem um método simples, fácil e seguro para o acesso venoso central através de dissecção da veia jugular externa. Este método deveria ser de interesse dos leitores envolvidos com o transplante de medula óssea e ser considerado também para crianças e/ou adultos que necessitem de cateter venoso central de longa permanência (externo ou totalmente implantável) devido a outras razões, como a nutrição parenteral ou a administração de agentes quimioterápicos.

\section{REFERENCES}

Bagwell, C. E. et al. (2000), Potentially lethal complications of central venous catheter placement. J. Pediatr. Surg., 35, 709-713.

Fischmeister, G. et al. (2000), Permanent tunneled silicone central venous catheters for autologous PBPC harvest in children and young adults. Bone Marrow Transplant, 26, 781-786.

Gauderer, M. W. L. (1992), Vascular access techniques and devices in the pediatric patient. Surg. Clin. North Am., 72, 1267-1298.

Hickman, R. O. et al. (1979), A modified right atrial catheter for access to the venous system in marrow transplant recipients. Surg. Gynecol. Obstet., 148, 871-875.

Lobe, T. E. et al. (1993), A "smart needle" to facilitate difficult vascular access in pediatric patients. $J$. Pediatr. Surg., 28, 1401-1402.

Nosher, J. L. et al. (1994), Tunneled central venous access catheter placement in the pediatric population: comparison of radiologic and surgical results. Radiology, 192, 265-268.

Slama, M. et al. (1997), Improvement of internal jugular vein cannulation using an ultrasound-guided technique. Intensive Care Med., 23, 916-919.

Stovroff, M. and Teague, W. G. (1998), Intravenous access in infants and children. Pediatr. Clin. North Am., 45, 1373-1393.

Received: August 13, 2003; Revised: December 02, 2003; Accepted: August 06, 2004. 